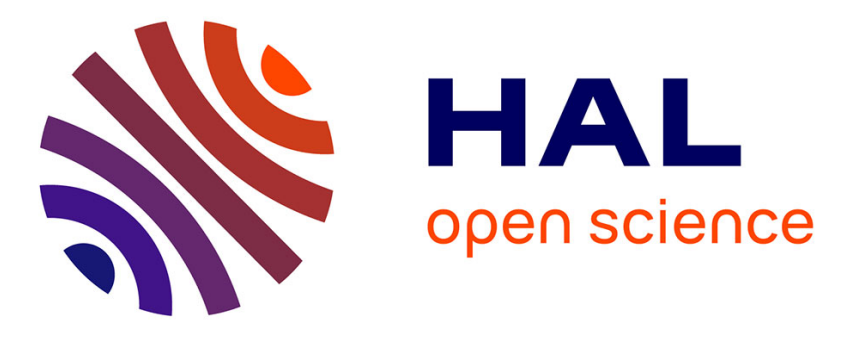

\title{
An Acyclic Oligoheteroaryle That Discriminates Strongly between Diverse G-Quadruplex Topologies
}

Florian Hamon, Eric Largy, Aurore Guødin-Beaurepaire, Myriam

Rouchon-Dagois, Assitan Sidibe, David Monchaud, Jean-Louis Mergny, Jean-François Riou, Chi-Hung Nguyen, Marie-Paule Teulade-Fichou, et al.

\section{To cite this version:}

Florian Hamon, Eric Largy, Aurore Guødin-Beaurepaire, Myriam Rouchon-Dagois, Assitan Sidibe, et al.. An Acyclic Oligoheteroaryle That Discriminates Strongly between Diverse GQuadruplex Topologies. Angewandte Chemie International Edition, 2011, 50 (37), pp.8745-8749. 10.1002/anie.201103422 . hal-02125709

\section{HAL Id: hal-02125709 https://hal.science/hal-02125709}

Submitted on 17 May 2019

HAL is a multi-disciplinary open access archive for the deposit and dissemination of scientific research documents, whether they are published or not. The documents may come from teaching and research institutions in France or abroad, or from public or private research centers.
L'archive ouverte pluridisciplinaire HAL, est destinée au dépôt et à la diffusion de documents scientifiques de niveau recherche, publiés ou non, émanant des établissements d'enseignement et de recherche français ou étrangers, des laboratoires publics ou privés. 


\title{
An Acyclic Oligoheteroaryle That Discriminates Strongly between Diverse G-Quadruplex Topologies**
}

\author{
Florian Hamon, Eric Largy, Aurore Guédin-Beaurepaire, Myriam Rouchon-Dagois, \\ Assitan Sidibe, David Monchaud, Jean-Louis Mergny, Jean-Francois Riou, Chi-Hung Nguyen, \\ and Marie-Paule Teulade-Fichou*
}

Quadruplex nucleic acids are secondary structures that may form in sequences containing guanine repeats. ${ }^{[1]}$ These structures are strongly suspected to interfere with the transfer and the maintenance of the genetic information and therefore are the focus of considerable attention. ${ }^{[2]}$ Quadruplexes may accommodate small synthetic compounds that could be used as probes to decipher their functions or as pharmacological agents to block various vital functions at the level of DNA or RNA. ${ }^{[3]}$ These synthetic ligands should fulfill an essential requirement to enable correlating their in cellulo biological effects to their quadruplex recognition ability, namely strong specificity for the targeted quadruplex combined with poor association to duplex DNA (ideally a difference of two orders of magnitude or more between the affinity constants is desired). ${ }^{[4]}$ Among the large number of quadruplex binders reported to date, the first one having met these criteria is telomestatin, a natural oxazole-based macrocycle (Scheme 1). ${ }^{[5]}$ Telomestatin is neutral, thus differentiating it from the vast majority of G-quadruplex binders that display fused aromatic skeletons with cationic charges. ${ }^{[3 a]}$ Overall the macrocyclic shape of telomestatin is recognized to dominate the interaction with quadruplex structures and to be responsible for its absence of affinity for duplex DNA. ${ }^{[6]}$ However, two recent studies have shown that cations may be involved in the binding of telomestatin with quadruplex DNA, thus suggesting the existence of a multivalent interaction that is

[*] Dr. F. Hamon, E. Largy, Dr. M. Rouchon-Dagois, Dr. D. Monchaud, Dr. C.-H. Nguyen, Dr. M.-P. Teulade-Fichou

UMR 176-Synthèse et Vectorisation de Biomolécules

Institut Curie, Campus-Bat 110-112

Université Paris-Sud, 91405 Orsay (France)

E-mail: mp.teulade-fichou@curie.fr

Homepage: http://umr176.curie.fr/en/MPTF

A. Guédin-Beaurepaire, Dr. J.-L. Mergny

IECB, Inserm U869, Laboratoire ARNA

33600 Pessac, (France)

A. Sidibe, Prof. J.-F. Riou

Inserm U656, CNRS UMR 7196, MNHN

43 rue cuvier 75005 Paris (France)

[***] We gratefully acknowledge D. Grierson for fruitful discussion, Marianne Blombled for LC-MS analysis, the MENRT for a PhD fellowship to M.R.D., the CNRS and the Institut Curie for a joint PhD fellowship to E.L., the LNCC for a grant (Equipe Labellisée) to J.F.R. and a PhD fellowship to A.S., and the ANR for financial support to F.H. (ANR-09-BLAN-0355 "G4Toolbox"). Nicolas Saettel is especially acknowledged for his help in the docking experiment. Supporting information for this article is available on the WWW under http://dx.doi.org/10.1002/anie.201103422.
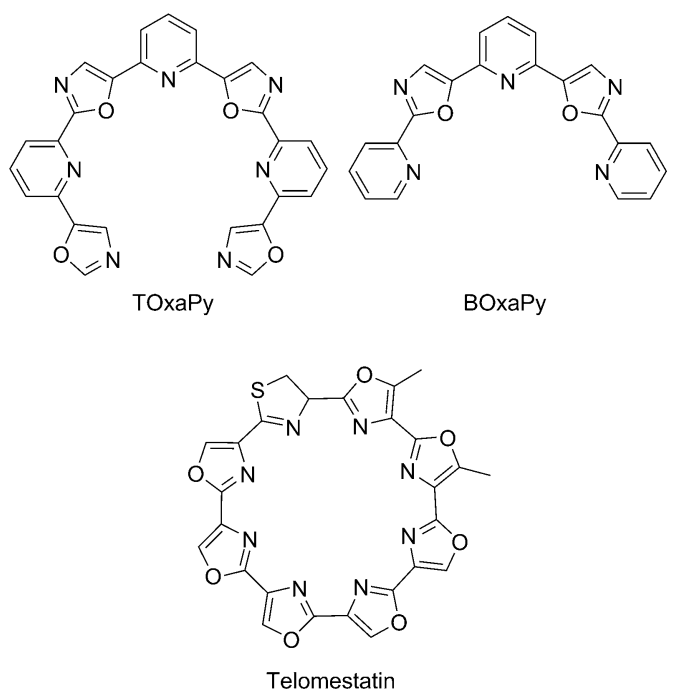

Scheme 1. Structure of telomestatin and of the new heteroaryles TOxaPy and BOxaPy (the new compounds have large conformational freedom and the bended shape represented above is only one possible conformation).

more complex than anticipated. ${ }^{[7]} \mathrm{Up}$ to recently, telomestatin remained accessible by an arduous multistep synthetic pathway. ${ }^{[8]}$ Although this method has been significantly optimized, ${ }^{[9]}$ the impressive antitumor activity of this natural product ${ }^{[10]}$ has prompted efforts to develop oxazole-based macrocyclic analogues. ${ }^{[1]}$ These synthetic macrocycles elicit quadruplex-interacting properties, but most of them require derivatization with cationic linkers to be active, which demonstrates that the macrocyclic shape is the essential determinant of selectivity.

To address this question of importance in the establishment of G-quadruplex recognition rules, we were keen to develop further the class of neutral oxazole-based quadruplex binders with a new family that features a nonmacrocyclic oligomeric scaffold with alternate oxazole and pyridine motifs (Scheme 1). In this series, the heptacyclic derivative TOxaPy was found to be totally devoid of affinity for duplex DNA while exhibiting an unprecedented binding preference for certain quadruplex topologies over others. In particular and remarkably, the new compound recognizes exclusively the human telomeric quadruplex in $\mathrm{Na}^{+}$-rich buffer and is not active in $\mathrm{K}^{+}$-rich buffer (see Figure $\mathrm{S} 1$ in the Supporting Information). This unique quadruplex binding profile is strongly dependent on the size of the oligomer, as the 
pentacyclic analogue BOxaPy does not associate to quadruplexes, and may result from groove interactions.

To achieve the synthesis of oligo-heteroaryles, we adopted a convergent procedure based on the cross-coupling of 2,6bis(oxazol-5-yl)pyridine (1) with 2-bromopyridine derivatives by the double $\mathrm{C}-\mathrm{H}$ activation of the oxazole rings (Scheme 2). ${ }^{[12]}$ Precursor 1 was obtained in two steps by the

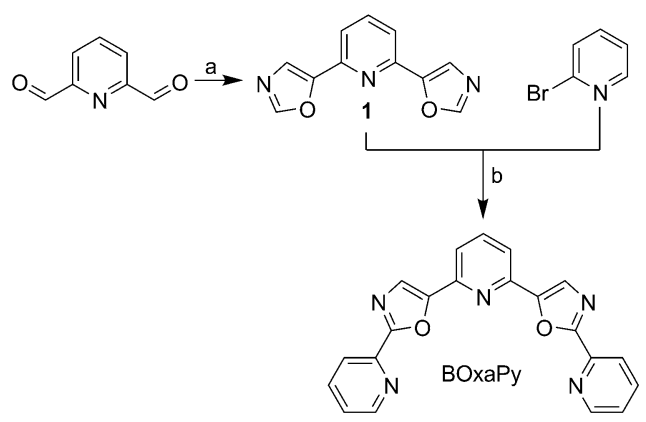

Scheme 2. First approach affording $\mathrm{BOxaPy}$ and TOxaPy as a mixture of isomers. a) TosMIC, $\mathrm{K}_{2} \mathrm{CO}_{3}, \mathrm{MeOH}, 50^{\circ} \mathrm{C}, 16 \mathrm{~h}(50 \%)$; b) Cul, $\mathrm{Pd}(\mathrm{OAc})_{2}, \mathrm{Cs}_{2} \mathrm{CO}_{3}, \mathrm{PCy}_{3} \cdot \mathrm{HBF}_{4}$, dioxane, $130^{\circ} \mathrm{C}, 24 \mathrm{~h}(45 \%)$; Tos$\mathrm{MIC}=p$-toluenesulfonylmethyl isocyanide; $\mathrm{Cy}=$ cyclohexyl.

oxidation of 2,6-lutidine with selenium dioxide to afford pyridine-2,6-dicarbaldehyde, ${ }^{[13]}$ which was submitted to Van Leusen conditions (see Scheme S1 in the Supporting Information). The coupling of $\mathbf{1}$ under classical conditions with two molar equivalents of 2-bromopyridine led to the pentaheteroaryle BOxaPy (bisoxazoletrispyridine). The same coupling reaction was carried out using 2-bromo-5-(pyridine-2yl)oxazole to prepare the heptaaryle homologue TOxaPy (tetraoxazoletrispyridine; structure shown in Scheme 3).

However, in this case the reaction product was found to be a mixture of TOxaPy and a geometric isomer differing only by one pyridine-oxazole junction (ca. 50:50 from HPLC analysis, Scheme S2 and Figure S2). This mixture results from two equivalent positions available for the second condensation as demonstrated by a deuteration experiment (see Scheme S3 and Figure S3). To obtain TOxaPy unambiguously, a new route was devised in which terminal oxazole moieties were synthesized from the corresponding pentacyclic bisformyl intermediate 4 (Scheme 3). In this approach, 1 was coupled with 2-bromo-6-(1,3-dioxolan-2-yl)pyridine 2 to afford the bisacetal precursor $\mathbf{3}$, which, after deprotection, afforded compound 4. The latter was converted into TOxaPy under treatment with TosMIC (overall yield 19\%; TosMIC $=p$ toluenesulfonylmethyl isocyanide).

The ability of the obtained oligomeric compounds to interact with the human telomeric quadruplex was first investigated by a FRET-melting assay (FRET = fluorescence resonance energy transfer) using the doubly labeled sequence F21T $\left[F A M-\mathrm{G}_{3}\left(\mathrm{~T}_{2} \mathrm{AG}_{3}\right)_{3}\right.$-Tamra.$^{[14]}$ Remarkably, TOxaPy induces a large stabilization of $\mathrm{F} 21 \mathrm{~T}$ in $\mathrm{Na}^{+}$conditions with $\Delta T_{1 / 2}=10.8^{\circ} \mathrm{C}$ (Figure 1a), whereas, in stark contrast, no significant stabilization was observed in $\mathrm{K}^{+}$conditions $\left(\Delta T_{1 / 2}\right.$ $\left.<1.0^{\circ} \mathrm{C}\right)$. A concentration-dependent FRET-melting experiment confirmed both the strong stabilizing ability of TOxaPy

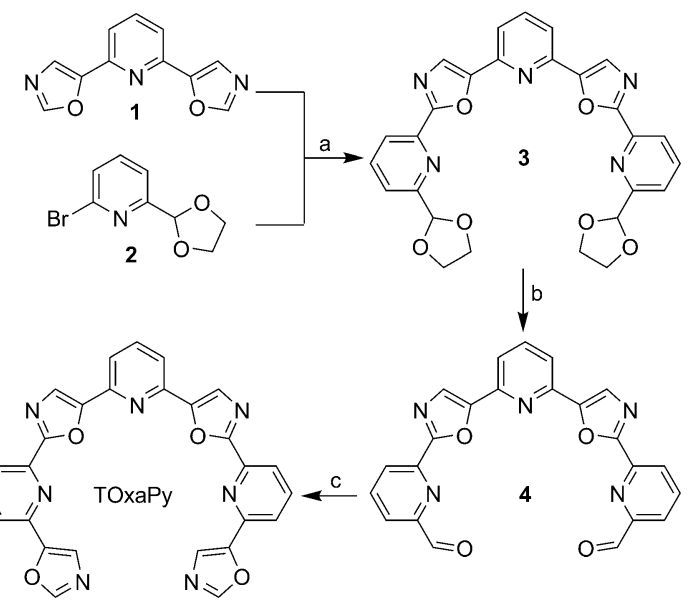

Scheme 3. Regiospecific synthesis of TOxaPy a) Cul, $\mathrm{Pd}(\mathrm{OAc})_{2}$, $\mathrm{Cs}_{2} \mathrm{CO}_{3}, \mathrm{PCy}_{3} \cdot \mathrm{HBF}_{4}$, dioxane, $130^{\circ} \mathrm{C}, 24 \mathrm{~h}(45 \%)$; b) $\mathrm{HCl}(2 \mathrm{M}), 110^{\circ} \mathrm{C}$, $2 \mathrm{~h},(84 \%)$; c) TosMIC, $\mathrm{K}_{2} \mathrm{CO}_{3}, \mathrm{MeOH}, 50^{\circ} \mathrm{C}, 16 \mathrm{~h}(50 \%)$.
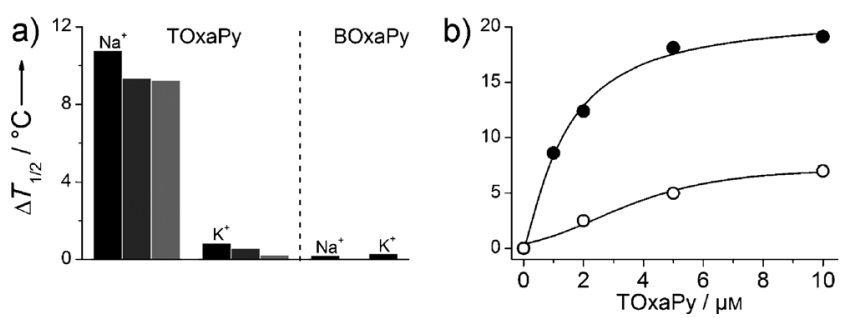

Figure 1. a) Left: Stabilization of F21T $(0.2 \mu \mathrm{M})$ by TOxaPy $(1 \mu \mathrm{M})$ alone (black bar) and in presence of ds26 (3 and $10 \mu \mathrm{M}$, dark and light gray bars) in $\mathrm{Na}^{+}$- or $\mathrm{K}^{+}$-rich buffer. Right: stabilization of F21T by BOxaPy $(1 \mu \mathrm{M})$ in the indicated cationic conditions. b) Stabilization of F21T as a function of TOxaPy concentration in $\mathrm{Na}^{+}-(\bullet)$ and $\mathrm{K}^{+}$-rich $(\circ)$ buffer (composition of the $\mathrm{Na}^{+}$- and $\mathrm{K}^{+}$-rich buffers is specified in the Supporting Information). The $y$ axis label in (a) also corresponds to (b).

in $\mathrm{Na}^{+}$(Figure $1 \mathrm{~b}$ ) and the poor effect in $\mathrm{K}^{+}$(around $+7^{\circ} \mathrm{C}$ at $10 \mu \mathrm{M})$. This behavior is remarkable as all known quadruplex binders exhibit no marked cation-dependence or, if so, show a stronger association in $\mathrm{K}^{+}$-rich buffer (see Figure S4). ${ }^{[14]}$ Finally, melting experiments indicate that the heptacyclic compound exhibits a very poor ability to associate to duplex DNA, since the stabilization of F21T is only marginally affected by the presence of the 26 base pair duplex competitor ds26 (Figure $1 \mathrm{a}$ left panel and Table S1). In addition, the shorter pentacyclic analogue BOxaPy appears unable to stabilize F21T irrespective of the cationic conditions (Figure $1 \mathrm{a}$, right panel).

Taken together, these results suggest that the neutral compound TOxaPy binds exclusively the telomeric quadruplex architecture(s) in sodium conditions and that this unprecedented behavior is strongly dependent on the size of the oligomeric scaffold, which plays a key role in the strength of the interaction.

We next conducted several experiments with TOxaPy to have a deeper insight into this unprecedented binding behavior. Interestingly, TOxaPy is characterized by an intense 
blue fluorescence in water (fluorescence quantum yield $\Phi_{\mathrm{F}}=$ $0.5)$ that is strongly quenched in the presence of DNA. Hence, fluorimetric titrations were conducted with the quadruplexforming oligonucleotide $22 \mathrm{AG}\left[5^{\prime}-\mathrm{AG}_{3}\left(\mathrm{~T}_{2} \mathrm{AG}_{3}\right)_{3}-3^{\prime}\right]$ and the resulting curves fully confirmed the much stronger binding of TOxaPy in $\mathrm{Na}^{+}$as compared to $\mathrm{K}^{+}$conditions (Figure 2 and Figure S5). Fitting of the titration curve in $\mathrm{Na}^{+}$indicates $1: 1$ binding stoichiometry with a $K_{\mathrm{d}}$ value in the submicromolar range $\left(K_{\mathrm{d}}=2 \times 10^{-7} \mathrm{M}^{-1}\right)$, whereas, in the case of $\mathrm{K}^{+}$, the flat shape of the curve is clearly indicative of a low-binding interaction.

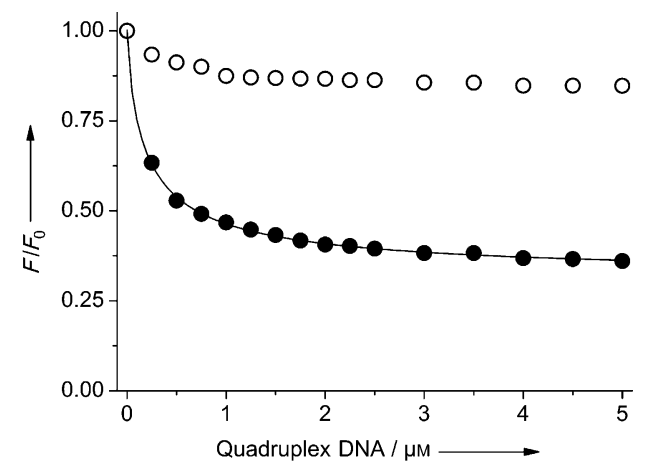

Figure 2. Fluorimetric titration of TOxaPy $\left(0.5 \mu \mathrm{M}, \lambda_{\text {exc }}: 340 \mathrm{~nm}\right)$ with 22AG. Plot of the fluorescence area enhancement $F / F_{0}(350-650 \mathrm{~nm})$ as a function of added DNA concentration in $\mathrm{Na}^{+}-(\bullet)$ or $\mathrm{K}^{+}$-rich (O) buffer conditions.

Since oxazoles may in principle coordinate to alkali metal cations, it was tempting to attribute the observed effect to the formation of a TOxaPy/ $\mathrm{Na}^{+}$complex prone to interact with the quadruplex, or conversely to a $\mathrm{TOxaPy} / \mathrm{K}^{+}$complex unfavorable to the interaction. However, direct coordination could not be observed by standard spectroscopic measurements as neither the absorption nor the fluorescence of the ligand was affected by large excess of both cations (data not shown). Therefore, fluorimetric titrations were conducted with two quadruplexes whose conformation is not dependent on the bound cation, namely the tetramolecular quadruplex $\left[5^{\prime}-\mathrm{TG}_{5} \mathrm{~T}-3^{\prime}\right]_{4}$, which has a parallel stranded conformation with five G-quartet layers, and the thrombin binding aptamer TBA $\left[5^{\prime}-G_{2} T_{2} G_{2} T T_{T} T_{2} T_{2} G_{2}-3^{\prime}\right]$, which has an antiparallel conformation with two G-quartet layers. Interestingly, strong binding of TOxaPy to the tetramolecular quadruplex was observed irrespective of the cation present in the medium, whereas, in contrast, no binding was detected with TBA again regardless of the cation (Figure S6).

These data clearly rule out the possibility that the $\mathrm{Na}^{+}-$ dependent stabilization is the result of a direct interference between TOxaPy and the cation and moreover points to the unusual behavior of TOxaPy that is actually able to recognize the antiparallel form of $22 \mathrm{AG}$ but not the antiparallel form of TBA both differing by the number of G-quartets layers (three and two, respectively) and loop arrangement.

To gain understanding into the surprising structural preferences of TOxaPy, G4-FID titrations were performed using the same DNA sequences. This assay is based on the competitive displacement of the fluorescent light-up probe thiazole orange (TO) by a putative ligand. ${ }^{[15]}$ The ligand association to a given DNA matrix results in fluorescence quenching of TO that reflects the binding affinity, the latter being quantified by the ligand concentration inducing $50 \%$ probe displacement $\left({ }^{\mathrm{G} 4} \mathrm{DC}_{50}\right)$.

The results of the G4-FID assay are shown in Figure 3. Clearly, the probe is strongly displaced in $\mathrm{Na}^{+}$conditions, whereas it is not in $\mathrm{K}^{+}$conditions or when the assay is carried

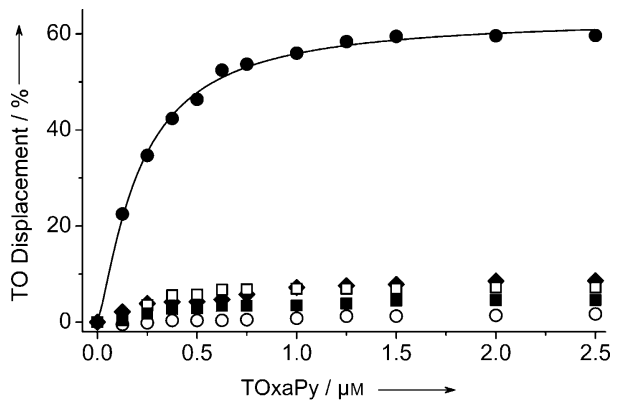

Figure 3. Plot of TO displacement vs. TOxaPy concentration with quadruplex DNA (22AG) in $\mathrm{Na}^{+}-(\bullet)$ or in $\mathrm{K}^{+}$-rich (०) buffer; TBA in $\mathrm{Na}^{+}-(\square)$ and in $\mathrm{K}^{+}$-rich ( $\square$ ) buffer, duplex ds26 ( $\bullet$ ) in $\mathrm{K}^{+}$-rich buffer; $[\mathrm{DNA}]=0.25 \mu \mathrm{M}, \mathrm{TO}=0.5 \mu \mathrm{M}$ with $22 \mathrm{AG}$ and TBA, and $0.75 \mu \mathrm{M}$ with ds26.

out with TBA or the control duplex ds26. However, TOxaPy is not able to displace completely the fluorescent marker, since the fluorescence decrease levels off at $60 \%$, thus preventing determination of ${ }^{\mathrm{G} 4} \mathrm{DC}_{50}$, which has poor significance in such case. Conversely, the partial displacement of TO strongly suggests that the competition might be indirect as a result of binding of TOxaPy to a site different from that of TO (loop, groove), thereby indicating a binding mode rather different from the classical $\pi$-stacking on external quartets. Since TO is poorly fluorescent in the tetramolecular quadruplex matrix, the latter was not evaluated by the same assay, but instead other well-known quadruplexes, that is, c-myc ${ }^{[16]}$ and c-kit $2^{[17]}$ were tested. Very interestingly, once again, we found that TOxaPy hardly displaces TO from these matrices (Figure S7). The poor binding ability of the ligand for these two quadruplexes was confirmed by very moderate stabilization measured by FRET-melting studies $\left(\Delta T_{1 / 2} \approx 5^{\circ} \mathrm{C}\right.$ in both cases; see Table S2).

On the whole, the results of the three assays are fully consistent, indicating the strong recognition of the $\mathrm{Na}^{+}$ conformation of the telomeric sequence and the inability of TOxaPy to bind the $\mathrm{K}^{+}$forms of the human telomeric quadruplex, the antiparallel TBA, and duplex DNA and the moderate recognition of c-myc and c-kit2.

Owing to its oligomeric structure TOxaPy has a high degree of flexibility and thus has the potential to adopt very diverse conformations, enabling adaptation to the geometric constraints of its DNA target. It cannot be excluded that this compound adopts a planar cyclic shape suitable for $\pi$-stacking on quartets (represented in Scheme 1) and that this structural organization may occur inside the quadruplex and be 
mediated by $\mathrm{Na}^{+}$, as was recently shown for telomestatin. However, this would not be consistent with the strong binding of $\left[\mathrm{TG}_{5} \mathrm{~T}\right]_{4}$ and the absence of binding of TBA, that both offer accessible external quartets prone to accommodate planar quadruplex binders. It is thus more likely that TOxaPy displays a more or less extended conformation that will favor a nontypical binding mode, presumably through interaction in grooves. Indeed, the latter provide hydrophobic pockets for ribbon-like oligomeric molecules, as shown recently. ${ }^{[18]}$ This hypothetic binding mode (represented in Figure S8) would explain the absence of binding to TBA that display short grooves ${ }^{[19]}$ As well, the absence of binding to the $\mathrm{K}^{+}$telomeric forms could reflect the predominance of $\mathrm{G} 4$ folds with inaccessible grooves, as is the case of the propeller parallel structure $^{[20]}$ or with too short grooves as featured by the basket-type two-quartet structure ${ }^{[21]}$ (Figure S1).

With these results in hand, we decided to evaluate the two oligoheteroaryles for their activity on the growth of several cancer cell lines. Remarkably, TOxaPy was found to inhibit strongly the proliferation of the cell lines with $\mathrm{IC}_{50}$ values (concentration required to inhibit $50 \%$ of the growth) lying down to the nanomolar range (Tables S3 and S4). Conversely, the pentacyclic analogue $\mathrm{BOxaPy}$ was poorly efficient even at high concentration (Table S3). This difference in activity is fully consistent with that observed in the FRET-melting assay, thereby underlying the crucial importance of the size of the oligomeric scaffold for both the quadruplex affinity in vitro and the cellular effects. Finally, these results indicate the efficient cellular uptake of TOxaPy and demonstrate its pharmacological potential, which may represent a basis for further developments in anticancer drug discovery.

In summary, using a straightforward and readily scalable synthetic pathway, we expanded the class of oxazole-based quadruplex ligands and showed the potential of acyclic derivatives for binding quadruplexes with a high and unprecedented specificity. Our findings evidence that a macrocyclic shape is not the only determinant to abolish duplex binding and that acyclic flexible oligomeric scaffolds may adapt specifically to quadruplexes. Importantly, the inability of certain quadruplexes (the $\mathrm{K}^{+}$telomeric form, TBA) to accommodate TOxaPy is highly indicative of differences in site accessibility, thereby suggesting the existence of hydrophobic pockets that could be used to anchor ligands specifically. The quadruplex recognition properties of TOxaPy will be further evaluated with the aim of understanding more in depth its interaction with quadruplexes.

Received: May 18, 2011

Published online: August 2, 2011

Keywords: DNA · G-quadruplexes · heterocycles . molecular recognition

[1] a) J. B. Chaires, FEBS J. 2010, 277, 1098-1106; b) D. J. Patel, A. T. Phan, V. Kuryavyi, Nucleic Acids Res. 2007, 35, 7429-7455.

[2] a) H. J. Lipps, D. Rhodes, Trends Cell Biol. 2009, 19, 414-422; b) S. Balasubramanian, S. Neidle, Curr. Opin. Chem. Biol. 2009 , $13,345-353$.
[3] a) D. Monchaud, M.-P. Teulade-Fichou, Org. Biomol. Chem. 2008, 6, 627-636; b) A. De Cian, L. Lacroix, C. Douarre, N. Temime-Smaali, C. Trentesaux, J.-F. Riou, J.-L. Mergny, Biochimie 2008, 90, 131-155; c) S. N. Georgiades, N. H. Abd Karim, K. Suntharalingam, R. Vilar, Angew. Chem. 2010, 122, 41144128; Angew. Chem. Int. Ed. 2010, 49, 4020-4034; d) T.-M. Ou, Y.-J. Lu, T. Jia-Heng, Z.-S. Zhang, K.-Y. Wong, L.-Q. Gu, ChemMedChem 2008, 3, 690-713; e) G. W. Collie, S. Sparapani, G. N. Parkinson, S. Neidle, J. Am. Chem. Soc. 2011, 133, $2721-$ 2728; f) S. Kumari, A. Bugaut, J. L. Huppert, S. Balasubramanian, Nat. Chem. Biol. 2007, 3, 218-221; g) M. Wieland, J. S. Hartig, Chem. Biol. 2007, 14, 757-763; h) S. Neidle, Curr. Opin. Struct. Biol. 2009, 19, 239-250.

[4] S. Neidle, FEBS J. 2010, 277, 1118-1125.

[5] a) K. Shin-ya, K. Wierzba, K.-i. Matsuo, T. Ohtani, Y. Yamada, K. Furihata, Y. Hayakawa, H. Seto, J. Am. Chem. Soc. 2001, 123, $1262-1263$; b) M.-Y. Kim, H. Vankayalapati, K. Shin-ya, K. Wierzba, L. H. Hurley, J. Am. Chem. Soc. 2002, 124, 2098-2099.

[6] D. Monchaud, A. Granzhan, N. Saettel, A. Guedin, J.-L. Mergny, M.-P. Teulade-Fichou, J. Nucleic Acids 2010, 525862.

[7] a) F. Rosu, V. Gabelica, N. Smargiasso, G. Mazzucchelli, K. ShinYa, E. De Pauw, J. Nucleic Acids 2010, 121259; b) S. Agrawal, R. P. Ojha, S. Maiti, J. Phys. Chem. B 2008, 112, 6828-6836; c) J. r. Linder, T. P. Garner, H. E. L. Williams, M. S. Searle, C. J. Moody, J. Am. Chem. Soc. 2011, 133, 1044-1051.

[8] T. Doi, M. Yoshida, K. Shin-ya, T. Takahashi, Org. Lett. 2006, 8, $4165-4167$.

[9] T. Doi, K. Shibata, M. Yoshida, M. Takagi, M. Tera, K. Nagasawa, K. Shin-ya, T. Takahashi, Org. Biomol. Chem. 2011, 9, 387-393.

[10] a) N. Temime-Smaali, L. Guittat, A. Sidibe, K. Shin-ya, C. Trentesaux, J.-F. Riou, PLoS One 2009, 4, e6919; b) H. Tahara, K. Shin-ya, H. Seimiya, H. Yamada, T. Tsuruo, T. Ide, Oncogene 2005, 25, 1955-1966.

[11] a) S. G. Rzuczek, D. S. Pilch, A. Liu, L. Liu, E. J. LaVoie, J. E. Rice, J. Med. Chem. 2010, 53, 3632-3644; b) C. M. Barbieri, A. R. Srinivasan, S. G. Rzuczek, J. E. Rice, E. J. LaVoie, D. S. Pilch, Nucleic Acids Res. 2007, 35, 3272-3286; c) M. Tera, H. Ishizuka, M. Takagi, M. Suganuma, K. Shin-ya, K. Nagasawa, Angew. Chem. 2008, 120, 5639-5642; Angew. Chem. Int. Ed. 2008, 47, 5557-5560; d) M. Tera, H. Ishizuka, M. Takagi, M. Suganuma, K. Shin-ya, K. Nagasawa, Angew. Chem. 2008, 120, 5639-5642; e) M. Tera, K. Iida, K. Ikebukuro, H. Seimiya, K. Shin-ya, K. Nagasawa, Org. Biomol. Chem. 2010, 8, 2749-2755.

[12] F. Besselievre, F. Mahuteau-Betzer, D. S. Grierson, S. Piguel, J. Org. Chem. 2008, 73, 3278-3280.

[13] A. Zaid, J.-S. Sun, C.-H. Nguyen, E. Bisagni, T. Garestier, D. S. Grierson, R. Zain, ChemBioChem 2004, 5, 1550-1557.

[14] A. De Cian, L. Guittat, M. Kaiser, B. Saccà, S. Amrane, A. Bourdoncle, P. Alberti, M.-P. Teulade-Fichou, L. Lacroix, J.-L. Mergny, Methods 2007, 42, 183-195.

[15] a) D. Monchaud, C. Allain, M.-P. Teulade-Fichou, Bioorg. Med. Chem. Lett. 2006, 16, 4842-4845; b) D. Monchaud, C. Allain, H. Bertrand, N. Smargiasso, F. Rosu, V. Gabelica, A. De Cian, J. L. Mergny, M. P. Teulade-Fichou, Biochimie 2008, 90, 1207-1223; c) E. Largy, F. Hamon, M.-P. Teulade-Fichou, Anal. Bioanal. Chem. 2011, 400, 3419-3427.

[16] a) A. Siddiqui-Jain, C. L. Grand, D. J. Bearss, L. H. Hurley, Proc. Natl. Acad. Sci. USA 2002, 99, $11593-11598$; b) A. T. Phan, Y. S. Modi, D. J. Patel, J. Am. Chem. Soc. 2004, 126, 8710-8716.

[17] V. Kuryavyi, A. T. Phan, D. J. Patel, Nucleic Acids Res. 2010, 38, 6757-6773.

[18] a) S. Cosconati, L. Marinelli, R. Trotta, A. Virno, S. De Tito, R. Romagnoli, B. Pagano, V. Limongelli, C. Giancola, P. G. Baraldi, L. Mayol, E. Novellino, A. Randazzo, J. Am. Chem. Soc. 2010,132, 6425-6433; b) Q. Li, J. Xiang, X. Li, L. Chen, X. Xu, Y. Tang, Q. Zhou, L. Li, H. Zhang, H. Sun, A. Guan, Q. Yang, S. 
Yang, G. Xu, Biochimie 2009, 91, 811-819; c) N. Ranjan, K. F. Andreasen, S. Kumar, D. Hyde-Volpe, D. P. Arya, Biochemistry 2010, 49, 9891-9903.

[19] R. F. Macaya, P. Schultze, F. W. Smith, J. A. Roe, J. Feigon, Proc. Natl. Acad. Sci. USA 1993, 90, 3745-3749.
[20] a) G. N. Parkinson, M. P. H. Lee, S. Neidle, Nature 2002, 417, 876-880; b) R. D. Gray, L. Petraccone, J. O. Trent, J. B. Chaires, Biochemistry 2010, 49, 179-194.

[21] K. W. Lim, S. Amrane, S. Bouaziz, W. Xu, Y. Mu, D. J. Patel, K. N. Luu, A. T. n. Phan, J. Am. Chem. Soc. 2009, 131, 43014309 . 